\title{
What Drives Prescribing of Asthma Medication to Children? A Multilevel Population-Based Study
}

\author{
Mira G. P. Zuidgeest, PharmD, $P b D^{1,3}$ \\ Liset van Dijk, $P b D^{2}$ \\ Peter Spreeuwenberg, $M A^{2}$ \\ Henriëtte A. Smit, MD, $P b D^{3}$ \\ Bert Brunekreef, $P b D^{4,5}$ \\ Hubertus G. M. Arets, MD, PbD \\ Madelon Bracke, PbD \\ Hubert G. M. Leufkens, PharmD, \\ $P b D^{1}$
}

'Division of Pharmacoepidemiology \& Pharmacotherapy, Utrecht Institute for Pharmaceutical Sciences (UIPS), Faculty of Science, Utrecht University, Utrecht, The Netherlands

${ }^{2}$ NIVEL (Netherlands Institute for Health Services Research), Utrecht, The Netherlands

${ }^{3}$ Centre of Prevention and Health Services Research, National Institute for Public Health and the Environment (RIVM), Bilthoven, The Netherlands

${ }^{4}$ Institute for Risk Assessment Sciences, Utrecht University, Utrecht, The Netherlands

${ }^{5}$ Julius Center for Health Sciences and Primary Care, University Medical Center, Utrecht, The Netherlands

${ }^{6}$ Department of Paediatric Pulmonology, Wilhelmina Children's Hospital, University Medical Centre, Utrecht, The Netherlands

Conflict of interest: The department employing authors M.G.P.Z, M.B. and H.G.M.L. has received an educational grant from GSK for the conduct of pharmacoepidemiological research. All other authors declare that they bave no conflict of interest.

\section{CORRESPONDING AUTHOR}

Bert Leufkens, PhD

Division of Pharmacoepidemiology \&

Pharmacotherapy

Utrecht University

PO Box 80082, 3508 TB

Utrecht, The Netherlands

h.g.m.leufkens@uu.nl

\begin{abstract}
PURPOSE Diagnosing asthma in children with asthmatic symptoms remains a challenge, particularly in preschool children. This challenge creates an opportunity for variability in prescribing. The aim of our study was to investigate how and to what degree patient, family, and physician characteristics influence prescribing of asthma medication in children.
\end{abstract}

METHODS We undertook a multilevel population-based study using the second Dutch national survey of general practice (DNSGP-2), 2001. Participants were 46,371 children aged 1 to 17 years belonging to 25,537 families registered with 109 general practitioners. Using a multilevel multivariate logistic regression analysis with 3 levels, our main outcome measure was the prescribing of asthma medication, defined as at least 1 prescription for $\beta_{2}$-adrenergic agonists, inhaled corticosteroids, cromones, or montelukast during the 1-year study period.

RESULTS We identified characteristics significantly associated with prescribing asthma medication on all 3 levels (child, family, and physician). The variance in prescribing among physicians was significantly higher with children who were younger than 6 years than with children aged 6 years and older $(95 \% \mathrm{Cl}, 3.5 \%$ $25.2 \%$ vs $2.4 \%-13.4 \%$ ). Several diagnoses other than asthma and asthmatic complaints were strongly associated with prescribing asthma medication, including bronchitis/bronchiolitis $(\mathrm{OR}=9.04 ; 95 \% \mathrm{Cl}, 7.57-10.8)$ and cough $(\mathrm{OR}=6.51$; $95 \% \mathrm{Cl}, 5.68-7.47)$.

CONCLUSIONS Our study shows a much higher variance in prescribing patterns among general practitioners for children younger than 6 years compared with older children, which could be a direct result of the diagnostic complexities found in young children with asthmatic symptoms. Thus diagnostic gaps may lead to more physician-driven prescribing irrespective of the clinical context.

Ann Fam Med 2009;7:32-40. DOI: 10.1370/afm.910.

\section{INTRODUCTION}

$\Lambda$ sthma in children has been recognized as a major clinical and public health problem. ${ }^{1,2}$ Reported data on the prevalence of asthma symptoms in children vary significantly, from $1 \%$ to more than $30 \%$ in different populations. ${ }^{3}$

Despite all scientific and clinical progress, diagnosing asthma in children and treating children with asthmatic symptoms remain a challenge. ${ }^{4-6}$ First, children often receive medication to reduce symptoms during wheezing episodes to prevent further exacerbations and to serve more or less as a diagnostic tool. At a young age, however, valid diagnostic possibilities for asthma are still limited. Although most children will eventually turn out to be transient wheezers, there is a lack of objective diagnostic tools to distinguish these transient wheezers from the true asthmatics. ${ }^{6}$ Second, the family of the child may play a role, for example, with its specific help-seek- 
ing behavior ${ }^{7}$ and a genetic influence on disease susceptibility. ${ }^{8}$ Last but not least, it is the treating physician who makes the decision whether to prescribe asthma medication. To aid in this decision, guidelines are available with information on how asthmatic symptoms in children should be treated and which kind of asthma medication should be used. ${ }^{9-11}$ There is general consensus that a diagnosis of asthma cannot be made with reasonable certainty earlier than the age of 5 to 6 years; therefore, different treatment recommendations are made for children who are younger than 5 to 6 years than for children aged 6 years and older. ${ }^{9-11}$

Prescribing asthma medication to children is the result of a complex interplay among the child, the caregivers or parents of the child, and the treating physician. Given the absence of clear diagnostic guidance in children, particularly in preschool children, variability in prescribing is to be expected. As a result, drug utilization studies describing actual use of asthma medicines in children show ample diversity in the applied therapies. ${ }^{12-14}$ Other studies have reported a mismatch between asthma medication use and a diagnosis of asthma. ${ }^{15-17}$ A key question driven by these observations is whether this diversity seen in pediatric asthma therapy is mainly determined by the patient itself, the family, or the treating physician. The attitude of the physician or preferences of the caregivers or parents could play a much larger role in the decisionmaking process at a young age, when the diagnosis is uncertain, than at an older age, when the diagnosis of asthma can be more firmly established.

The aim of this study was to investigate how and to what degree prescribing asthma medication to children is influenced by patient, family, and physician characteristics. We investigated to what extent variance in prescribing is associated with differences among children, how much variance can be attributed to the family or physician or both, and whether these variances differ for younger and older children.

\section{METHODS}

\section{Setting and Study Population}

In the Netherlands children with asthmatic symptoms and morbidity are primarily seen by the physicians in general practice. This study was therefore undertaken within the framework of the Second Dutch National Survey of General Practice (DNSGP-2). This nationwide survey was carried out in 2001 by the NIVEL (Netherlands Institute for Health Services Research) in cooperation with the National Institute for Public Health and the Environment (RIVM). Practices already participating in the Dutch National Information Network of General Practice were invited to participate in this study because of their experience in the use of electronic medical records. All practices within the DNSGP-2 made use of electronic medical records. The participating general practitioners (GPs) were representative of all Dutch GPs. ${ }^{18}$ A pilot study also showed no differences in practice style between GPs participating in a registration network and those who were not. ${ }^{19}$

The DNSGP-2 survey has been described in detail elsewhere. ${ }^{18,20}$ In short, 195 GPs in 104 practices serving approximately 400,000 patients registered all physician-patient contacts during 12 consecutive months. The DNSGP-2 provides data on all diagnoses made and prescriptions written by the GP. Every single health problem reported within a consultation was coded by the GP using the International Classification for Primary Care (ICPC). ${ }^{21}$ Additional information on patient and GP characteristics was collected through questionnaires. In the Netherlands all noninstitutionalized inhabitants are registered in a single general practice, with few changes over time. The DNSGP-2 survey was carried out according to Dutch legislation on privacy. The privacy regulation of the study was approved by the Dutch Data Protection Authority.

For the present study we analyzed data from 72 GP practices. The other practices were excluded for various reasons: 20 practices were excluded because the information on which patient belongs to which individual GP was not available, 10 because of incomplete data collection on morbidity items, and 2 more because of lack of information on GP characteristics. The remaining 109 GPs within the 72 practices did not differ significantly from the total group of GPs participating in the DNSGP-2 except for a higher percentage of solo practices (because of our selection criterion of including only patients that could be linked to a specific GP).

A total of 1,804 children (3.7\%) who could not be linked to a single family were also excluded. The final study population consisted of 46,371 children aged 1 to 17 years within 25,537 families, belonging to 109 GPs within 72 practices. Children, families, and GPs seem to be representative for the Dutch situation on basic characteristics. ${ }^{18,20}$

\section{Measurements}

Outcome Variable: Prescribing of Asthma Medication Drug prescriptions were registered by the GP according to the Anatomic Therapeutic Chemical Classification system. ${ }^{22}$ The following medications were considered asthma medication: inhaled and oral short-acting $\beta_{2}$-agonists, inhaled long-acting $\beta_{2}$-agonists, inhaled corticosteroids, inhaled cromones, and montelukast. We determined whether a child from the study population received at least 1 prescription for 1 of these med- 
icine groups in the year under study (ie, 2001), calling them "children prescribed asthma medication."

\section{Child Characteristics}

At the level of the individual child, the following variables were taken into account: age (categorized into children younger than 6 years and children aged 6 years and older to conform with the guidelines), sex, the number of prescriptions a child received for antibiotics in the year under study, the number of prescriptions a child received for oral glucocorticosteroids in the year under study, the number of contacts a child had with the GP in the year under study, and whether a child had at least 1 referral for respiratory complaints/diseases or to a lung specialist in the year under study. Every health problem reported during a consultation was coded by the GP using the ICPC. ${ }^{21} \mathrm{We}$ included the following ICPC diagnoses of respiratory complaints and diseases as dichotomous variables: R02 (shortness of breath/dyspnea), R03 (wheezing), R05 (cough), R74 (acute upper respiratory tract infection), R78 (acute bronchitis/bronchiolitis), R81 (pneumonia), R96 (asthma), and R97 (allergic rhinitis). If a child had at least 1 consultation coded with 1 of these ICPC codes, then the dichotomous variable for that specific code for that child would be positive.

\section{Family Characteristics}

At the family level the following variables were taken into account: ethnicity (whether 1 or both parents had a non-Western cultural background based on the country of birth), the highest social economic status of the parent(s) using the International Socio-Economic Index of Occupational Status, and parental asthma (at least 1 parent with a registered ICPC code R96 during the study period).

\section{GP Characteristics}

At the GP level the following variables were taken into account: age; sex; practice type (solo vs group practice); degree of urbanization of practice location (as classified by Statistics Netherlands on a 5-point scale), GP information system used to register contacts, prescriptions, etc, whether the GP is a dispensing doctor (a doctor, authorized or required by the Health Authority to provide pharmaceutical services to his or her patients); whether the GP is working full-time or part-time by the number of full-time equivalents (FTEs); workload of the GP (total number of patients divided by the number of FTEs per 1,000 patients); prescribing volume of the GP (average number of prescriptions issued per patient during 1 year); proportion of 0 - to 17-year-old patients per GP; and the proportion of children with asthma diagnosis per GP.
We divided the GPs into 2 groups: those who within their patient population of children prescribed asthma medication to $7.4 \%$ of children or less (the average at the GP level is $7.4 \%$ ), and those who prescribed asthma medication to more than $7.4 \%$ of children .

\section{Statistical Analyses}

We performed a multilevel logistic regression analysis with 3 levels, namely, children within families clustered within GPs, which enabled us to study not only the influence of the child, family, and GP characteristics on asthma medication use in children simultaneously, but also the variance in prescribing at the 2 higher levels. The variance at the level of the child was not determined, as the outcome measure is dichotomous: a child either receives asthma medication or not.

The association between prescribing asthma medication and the variables described above was first tested by univariate analysis for each variable. Only variables significantly associated $(P<.05)$ with prescribing asthma medication were included in the multivariate analysis. All variables that no longer showed a significant association in the multivariate analysis were excluded. A sensitivity analysis including all child characteristics irrespective of significance showed that including the nonsignificant variables did not alter the estimates for the significant variables. The child characteristics of sex and all diagnoses of respiratory complaints and diseases were tested for an age interaction.

The multivariate analysis was computed in several steps to differentiate between the influence of child, family, and GP characteristics on the various estimates. Step 1, the empty model, gives the unexplained variance at the upper 2 levels (family and GP) without correcting for any differences that might exist in the population of children belonging to these families and these GPs. In step 2 we separated the variance in prescribing at the GP level and at the family level for children younger than 6 years and older children. At each level this analysis rendered a unique variance according to age-group and a covariance. If the covariance turned out to be much higher than the 2 unique variances at a certain level, separating the variance for the 2 age-groups at this level was not meaningful. In step 3 we added the child characteristics (including the age-interaction terms) to the model. This step serves 2 purposes: (1) to make the populations seen by the GP and belonging to a family as similar as possible, and (2) to determine which child characteristics are associated with prescribing asthma medication. The variance in this model is the variance unexplained by the child characteristics introduced in the model. In step 4 we added the family characteristics to the model. In step 5 we added the GP characteristics to the model. 
The variables included in the models described here were rescaled by subtracting the mean, so that the intercepts represent prescribing asthma medication to the average child. The percentage of children receiving asthma medication can be calculated by taking the inverse logit of the intercept. The association between characteristics on all 3 levels and prescribing asthma medication is expressed using odds ratios) and 95\% confidence intervals. The 95\% confidence interval of prescribing asthma medication at the GP level can be calculated for each age-group using the sum of the unique variance of that age-group and the covariance. All models were estimated using multilevel logistic regression, with PQL (penalized quasi-likelihood), 1st order, and constrained level-1 variance (MLwinN 2.02; Centre for Multilevel Modeling, University of Briston, Bristol, England).

\section{RESULTS}

\section{Characteristics of the Study Population}

Table 1 displays the characteristics of the study population at the child level and the results for the univariate analyses. During the year under study $7.3 \%$ of all children $(n=3,374)$ received asthma medication. All child characteristics were significantly associated with prescribing asthma medication when tested univariately. An overview of the applied therapies stratified by age-groups is displayed in Table 2 . We see that prescribing asthma medication declines with the rising age of the child. Short-acting $\beta_{2}$-agonists and inhaled corticosteroids were the medicine groups most prescribed at all ages. The children within our study population belonged to 3,081 families (Table 3); therefore, in $12.1 \%$ of the families, 1 or more children were prescribed asthma medication. The characteristics of the GPs are displayed in Table 4.

\section{The Multivariate Model}

Table 5 shows the stepwise-built, multivariate, multilevel, logistic regression model. We found that in the empty model the variance at the family level $(0.567)$ was much higher than the variance at the GP level (0.119).

\section{Comparing 2 Age-Groups}

When separating the variance in prescribing at the GP level for children younger than 6 years and for older children (model 1) we found that the variance is significantly higher $\left(\chi^{2}=7.3\right)$ in younger children than in older children. This age influence was not found at the family level; at this level the covariance was much higher than the 2 unique variances (model

Table 1. Child Characteristics and Results From the Univariate Analyses

\begin{tabular}{|c|c|c|c|}
\hline Child Characteristics & $\begin{array}{l}\text { Children Without an } \\
\text { Asthma Prescription } \\
\qquad(n=42,997)\end{array}$ & $\begin{array}{l}\text { Children Prescribed } \\
\text { Asthma Medication } \\
\qquad(n=3,374)\end{array}$ & OR $(95 \% \mathrm{Cl})$ \\
\hline Mean age (SD; range), y & $9.1(4.8 ; 1-17)$ & $7.7(4.9 ; 1-17)$ & $0.94^{\mathrm{a}}(0.93-0.95)$ \\
\hline Age $<6$ y, No. (\%) & $11,948(25.8)$ & $1,386(41.1)$ & $1.82^{\mathrm{a}}(1.69-1.96)$ \\
\hline Sex, male, No. (\%) & $21,798(50.7)$ & $1,922(57.0)$ & $1.29^{a}(1.20-1.39)$ \\
\hline Antibiotic prescriptions, No. (SD; range) ${ }^{\mathrm{b}}$ & $0.2(0.6 ; 0-13)$ & $0.6(1.0 ; 0-12)$ & $1.85^{\mathrm{a}}(1.77-1.93)$ \\
\hline Oral corticosteroid prescriptions, No. (SD; range) ${ }^{b}$ & $0.003(0.11 ; 0-12)$ & $0.046(0.26 ; 0-5)$ & $4.69^{a}(3.59-6.12)$ \\
\hline Contacts with GP, No. (SD; range) ${ }^{c}$ & $2.1(2.6 ; 0-35)$ & $5.2(4.0 ; 0-34)$ & $1.30^{\mathrm{a}}(1.29-1.31)$ \\
\hline Children with 0 contacts in registration year, No. (\%) & $13,786(32.1)$ & $129(3.8)$ & - \\
\hline Referrals, No. $(\%)^{\mathrm{d}}$ & $93(0.3)$ & $94(3.6)$ & $13.0^{\mathrm{a}}(12.2-13.9)$ \\
\hline \multicolumn{4}{|l|}{ Registered diseases and complaints, ${ }^{e}$ No. (\%) } \\
\hline Asthma & $227(0.5)$ & $1,739(51.5)$ & $260^{\mathrm{a}}(221-305)$ \\
\hline Shortness of breath/dyspnea & $92(0.2)$ & $144(4.3)$ & $21.1^{\mathrm{a}}(15.9-28.1)$ \\
\hline Wheezing & $16(0.0)$ & $63(1.9)$ & $55.2^{\mathrm{a}}(30.7-99.2)$ \\
\hline Cough & $2082(4.8)$ & $873(25.9)$ & $6.90^{\mathrm{a}}(6.26-7.59)$ \\
\hline Acute bronchitis/ bronchiolitis & $769(1.8)$ & $622(18.4)$ & $13.5^{\mathrm{a}}(11.9-15.3)$ \\
\hline Acute URTI & $3,267(7.6)$ & $674(20.0)$ & $3.06^{\mathrm{a}}(2.78-3.38)$ \\
\hline Pneumonia & $241(0.6)$ & $133(3.9)$ & $7.24^{\mathrm{a}}(5.74-9.15)$ \\
\hline Allergic rhinitis & $1,029(2.4)$ & $252(7.5)$ & $3.24^{\mathrm{a}}(2.78-3.77)$ \\
\hline $\begin{array}{l}\mathrm{Cl}=\text { confidence interval; GP }=\text { general practitioner; } \mathrm{ICPC}=\text { Inte } \\
\text { a Significant values } P<.05 \text {. } \\
{ }^{\mathrm{b}} \text { Average number of prescriptions issued per patient during } 1 \\
\text { 'Average number of contacts with GP during } 1 \text { year. } \\
\text { d Referrals for respiratory complaints/diseases or to a lung spec } \\
\text { e Dichotomous variables of the ICPC codes R02 (shortness of b } \\
\text { bronchitis/bronchiolitis), R81 (pneumonia), R96 (asthma), and }\end{array}$ & $\begin{array}{l}\text { /dyspnea), R03 (wheezing), RO } \\
\text { (allergic rhinitis). }\end{array}$ & ugh), R74 (acute upper respira & tract infection), R78 (acute \\
\hline
\end{tabular}


Table 2. Prescription of Asthma Medication by Age-Group and Type of Medication

\begin{tabular}{|c|c|c|c|c|c|c|c|}
\hline \multirow[b]{2}{*}{ Medication Type } & \multicolumn{7}{|c|}{ Age-Groups, Years } \\
\hline & $\begin{array}{c}1-2 \\
n=5,293\end{array}$ & $\begin{array}{c}3-5 \\
n=8,041\end{array}$ & $\begin{array}{c}6-8 \\
n=8,335\end{array}$ & $\begin{array}{c}9-11 \\
n=8,350\end{array}$ & $\begin{array}{c}12-14 \\
n=8,196\end{array}$ & $\begin{array}{c}15-17 \\
n=8,156\end{array}$ & $\begin{array}{c}\text { Total } \\
\mathrm{n}=46,371\end{array}$ \\
\hline All asthma medication, $\%$ & 10.9 & 10.1 & 7.0 & 6.1 & 5.7 & 5.2 & 7.3 \\
\hline \multicolumn{8}{|l|}{ Medication groups, \% } \\
\hline SABA & 8.0 & 7.0 & 4.9 & 4.5 & 4.5 & 3.6 & 5.3 \\
\hline ICS & 5.9 & 7.0 & 4.8 & 4.0 & 3.2 & 3.0 & 4.5 \\
\hline LABA & 0.1 & 0.3 & 0.5 & 0.7 & 0.6 & 0.6 & 0.5 \\
\hline Cromones & 0.8 & 0.5 & 0.1 & 0.1 & 0.1 & 0.1 & 0.2 \\
\hline Montelukast & 0.0 & 0.1 & 0.1 & 0.1 & 0.0 & 0.1 & 0.1 \\
\hline \multicolumn{8}{|l|}{ Therapy groups, \%a } \\
\hline SABA & 38.6 & 25.7 & 29.2 & 32.4 & 41.9 & 39.1 & 33.4 \\
\hline ICS & 20.7 & 24.7 & 24.3 & 18.7 & 15.1 & 21.9 & 21.3 \\
\hline$S A B A+I C S$ & 33.2 & 43.2 & 40.9 & 40.4 & 36.2 & 30.2 & 38.1 \\
\hline Other medicines & 7.5 & 6.5 & 5.6 & 8.6 & 6.8 & 8.8 & 7.2 \\
\hline
\end{tabular}

$\mathrm{ICS}=$ inhaled corticosteroids; $\mathrm{LABA}=$ long-acting $\beta_{2}$-agonists; SABA = short-acting $\beta_{2}$-agonists.

a We calculated percentage of children using some sort of asthma medication, not percentage of total population; therapy groups therefore add up to $100 \%$. Therapy groups are defined as follows: SABA = monotherapy with short-acting $\beta_{2}$-agonists; ICS = monotherapy with inhaled corticosteroids; SABA + ICS = combination therapy of these 2 medication groups ( $10.3 \%$ of children in this group also received 1 or more other asthma medicines, of which $82 \%$ were $L A B A)$; other medicines $=$ all other therapies.

Table 3. Family Characteristics and Results From the Univariate Analyses

\begin{tabular}{|c|c|c|c|}
\hline Family Characteristics & $\begin{array}{l}\text { No Child With Asthma } \\
\text { Medication Within Family } \\
\qquad(n=22,456)\end{array}$ & $\begin{array}{l}\geq 1 \text { Child Within Family } \\
\text { With Asthma Prescription } \\
\qquad(n=3,081)\end{array}$ & OR $(95 \% \mathrm{CI})$ \\
\hline $\begin{array}{l}1 \text { or both parents non-Western cultural } \\
\text { background, No. (\%) }\end{array}$ & $1,834(10.6)$ & $275(11.1)$ & $1.01(0.87-1.17)$ \\
\hline Mean SES highest (SD; range) ${ }^{\mathrm{b}}$ & $50.4(15.5 ; 16-87)$ & $49.5(15.4 ; 16-87)$ & $1.00(0.99-1.00)$ \\
\hline Parental asthma, No. (\%) & $821(3.7)$ & $256(8.3)$ & $2.33^{d}(1.90-2.85)$ \\
\hline \multicolumn{4}{|c|}{$\begin{array}{l}\text { a Ethnicity based on the country of birth. } \\
\text { b The highest SES of parent(s) using the International Socio-Economic Index of Occupational Status. } \\
\text { ' At least } 1 \text { parent with registered ICPC code for asthma during the study period. } \\
\text { d Significant values } P<.05 \text {. }\end{array}$} \\
\hline
\end{tabular}

not shown). In children younger than 6 years, GPs prescribed asthma medication to $9.9 \%$ of children (95\% CI, 3.5\%-25.2\%); in the older age-group they prescribed asthma medication to $5.8 \%$ of children (95\% CI, 2.4\%-13.4\%). The correlation between the 2 age-groups at the GP level was 0.83 , indicating that GPs who tended to prescribe asthma medication to young children more often also tended to do so for older children.

\section{Association Between Child Characteristics and Prescribing}

The next step was to add the child characteristics to the model (model 2). In this model the correlation between the variances for the 2 age-groups at the GP level increased to 0.89 , but the unique variances were still significantly different $\left(\chi^{2}=9.5\right)$. Model 2 also shows that the different complaints and disease diagnoses were strongly related to prescribing asthma medication. Children with diagnosed acute bronchitis/bronchiolitis were much more likely to receive asthma medication than was the average child (OR $=9.04 ; 95 \% \mathrm{CI}$, 7.5710.8), as were children experiencing shortness of breath $(\mathrm{OR}=20.7$; 95\% CI, 14.3-29.9), wheezing $(\mathrm{OR}=51.5$; 95\% CI, 24.7-107), or cough $(\mathrm{OR}=6.51 ; 95 \% \mathrm{CI}, 5.68$ 7.47). The number of antibiotic prescriptions, the number of oral corticosteroid prescriptions, and referrals were no longer significantly associated with prescribing asthma medication in the multivariate analyses.

Although children younger than 6 years were more frequently prescribed asthma medication, no significant age interactions were found for sex of the child or any of the diagnoses. From the intercept in model 2, we see that when correcting for child characteristics, young children no longer had a higher chance of receiving asthma medication than older children. 


\begin{tabular}{|c|c|c|c|}
\hline GP Characteristics & $\begin{array}{l}\text { GPs Prescribing } \\
\text { Asthma Medication } \\
\text { Average and } \\
\text { Below Average } \\
(\mathrm{n}=58)^{\mathrm{a}}\end{array}$ & $\begin{array}{l}\text { GPs Prescribing } \\
\text { Asthma Medication } \\
\text { Above Average } \\
(n=51)^{\mathrm{a}}\end{array}$ & OR (95\% Cl) \\
\hline Mean age (SD; range), y & $47.6(5.7 ; 36-59)$ & $46.2(6.2 ; 33-56)$ & $1.00(0.99-1.01)$ \\
\hline Sex, male, No. (\%) & $50(86.2)$ & $37(72.6)$ & $0.83(0.69-1.00)$ \\
\hline Practice type, solo, No. (\%) & $27(46.6)$ & $20(39.2)$ & $0.88(0.75-1.02)$ \\
\hline Urban practice location, mean (SD; range) ${ }^{b}$ & $2.8(1.4 ; 1-5)$ & $3.1(1.0 ; 1-5)$ & $1.03(0.98-1.10)$ \\
\hline Mean FTE (SD; range) ${ }^{c}$ & $0.91(0.15 ; 0.5-1.0)$ & $0.88(0.17 ; 0.5-1.0)$ & $0.79(0.48-1.28)$ \\
\hline Dispensing doctor, No. $(\%)^{d}$ & $5(8.6)$ & $3(5.9)$ & $0.97(0.73-1.29)$ \\
\hline Workload, mean (SD; range) ${ }^{e}$ & $2.8(0.7 ; 1.4-5.5)$ & $2.6(0.6 ; 1.3-4.8)$ & $0.89(0.80-1.00)$ \\
\hline Prescribing volume, mean (SD; range) ${ }^{\dagger}$ & $1.5(0.5 ; 0.05-2.7)$ & $1.8(0.5 ; 0.9-3.2)$ & $1.5^{9}(1.38-1.75)$ \\
\hline$\geq 25 \%$ of patients $0-17$ y, No. $(\%)^{\mathrm{h}}$ & $15(25.9)$ & $6(11.8)$ & $0.77^{9}(0.64-0.93)$ \\
\hline Children with an asthma diagnosis, \% (SD; range) & $3.5(1.4 ; 0.8-7.3)$ & $5.4(2.1 ; 1.9-11.6)$ & $1.10^{9}(1.07-1.14)$ \\
\hline \multicolumn{4}{|c|}{$\mathrm{Cl}=$ confidence interval $\mathrm{GP}=$ general practitioner; $\mathrm{FTE}=$ full-time equivalent; $\mathrm{OR}=$ odds ratio. } \\
\hline \multicolumn{4}{|c|}{$\begin{array}{l}\text { a To display the GP characteristics, we divided the GPs into } 2 \text { groups: those who prescribed asthma medicaton to the average percentage of children or less, and those } \\
\text { who prescribed above average (which, on the GP level, is } 7.4 \% \text { ) within their childhood patient population. } \\
\text { b As classified by Statistics Netherlands on a } 5 \text {-point scale, in which } 1=\text { high level of urbanizaton and } 5=\text { low urbanization. } \\
\text { ' Full-time or part-time working in number of FTEs. } \\
\text { d Authorized or required by the Health Authority to provide pharmaceutical services to his/her patients. } \\
\text { e Total number of patients divided by the number of FTEs per } 1,000 \text { patients. } \\
\text { A Average number of prescriptions issued per patient during } 1 \text { year. } \\
\text { g Significant values } P<.05 \text {. } \\
\text { h GPs with } 25 \% \text { or more of their total patient population of children aged } 0-17 \text { years. }\end{array}$} \\
\hline
\end{tabular}

\section{Taking Into Account the Family and GP Characteristics}

Model 3 is the final model and includes both the family and the GP characteristics. On the family level parental asthma was the only variable significantly correlated with prescribing asthma medication in the univariate analyses (Table 3 ), and this association was sustained in the multivariate model, where we adjusted for asthma diagnosis of the child ( $\mathrm{OR}=1.74 ; 95 \% \mathrm{CI}, 1.41-2.15)$.

Adding family and GP characteristics did not have a significant impact on the associations of the child's characteristics. This final model shows that in older children about one-half of the unexplained variance at the 2 upper levels occurs at the GP level, and the other one-half occurs at the family level (intraclass correlation $=0.51$ ). In younger children, however, the intraclass correlation was 0.64 ; thus, more of the unexplained variance lies on the GP level in this age-group.

Further analysis of the GP characteristics showed that GPs who prescribe more medication in general (the average number of prescriptions per patient per GP) prescribe more asthma medication as well $(\mathrm{OR}=1.99 ; 95 \% \mathrm{CI}, 1.60-2.47)$. GPs who serve a relatively large childhood patient population (GPs for whom more than $25 \%$ of their total patient population consisted of children) were less likely to prescribe asthma medication to the average child $(\mathrm{OR}=0.59$; 95\% CI, 0.44-0.78) as were GPs who had a higher percentage of children diagnosed with asthma within their patient population $(\mathrm{OR}=0.88 ; 95 \% \mathrm{CI}$, 0.83-0.93).

\section{DISCUSSION}

Our results show that a substantial number of children received asthma medication during the 1-year study period (7.3\%). Through studying the influence of the child, family, and GP characteristics simultaneously in a multilevel fashion, we were identified characteristics at all 3 levels that were significantly associated with prescribing asthma medication.

\section{Comparing 2 Age-Groups}

Based on the assumption that a diagnosis of asthma can be made with more certainty from the age of 6 years and onward, we expected to find more differences among GPs when prescribing asthma medications to children younger than 6 years than when prescribing to older children. Indeed, we found that the variance in prescribing among GPs was much higher with young children than with children aged 6 years and older. Only a small part of the difference in prescribing between these 2 age categories could be attributed to differences in the characteristics of the child. Our findings are in line with the current gap in the diagnosis of asthma particularly in preschool children, ${ }^{6,23,24}$ despite the ongoing search for better diagnostics. Such a gap provides ample opportunity for interphysician vari- 
ance in prescribing asthma medications based on personal preferences and prescribing attitudes in general. Related to this aspect was the finding that the overall medication prescribing volume of the GP was positively associated with prescribing asthma medications irrespective of complaints and illnesses of the child.

\section{Family Influence}

We also found that family influence on prescribing asthma medication to children was substantial. These findings are in line with reports of genetic influence on disease susceptibility, ${ }^{8}$ health-seeking behavior, ${ }^{7,25}$ and the attitude of the caregivers or parents regarding medication use. ${ }^{26}$ In our study, we found that parental asthma was positively associated with prescribing asthma medications. Since guidelines concerning asthma treatment state that parental asthma status should be taken into account when evaluating asthmatic symptoms in children, ${ }^{9-11}$ this finding is not unexpected. Moreover, we found that every additional contact with the GP renders a $10 \%$ increased chance of receiving asthma medication, indicating that healthseeking behavior of the family has a relevant impact on the treatment of the child.

Table 5. Multilevel Logistic Regression Analyses With 3 Levels: Child, Family, and General Practitioner (GP)

\begin{tabular}{|c|c|c|c|c|}
\hline Explanatory Variables & $\begin{array}{l}\text { Empty Model } \\
\text { Intercept (SE) }\end{array}$ & $\begin{array}{c}\text { Model } 1^{\mathrm{a}} \\
\text { Intercept (SE) }\end{array}$ & $\begin{array}{l}\text { Model } 2^{a, b} \\
\text { Intercept (SE) }\end{array}$ & $\begin{array}{c}\text { Model } 3^{a, b} \\
\text { Intercept (SE) }\end{array}$ \\
\hline Age $1-17$ y & $-2.580(0.039)$ & & & \\
\hline Age $1-5$ y & & $-2.210(0.054)$ & $-3.629(0.100)$ & $-3.645(0.091)$ \\
\hline \multirow[t]{2}{*}{ Age $6-17$ y } & & $-2.779(0.039)$ & $-3.573(0.071)$ & $-3.605(0.060)$ \\
\hline & & & OR $(95 \% \mathrm{CI})$ & OR $(95 \% \mathrm{CI})$ \\
\hline Sex, male & & & $1.25(1.13-1.39)$ & $1.25(1.13-1.39)$ \\
\hline Shortness of breath/dyspnea & & & $20.7(14.3-29.9)$ & $20.2(13.9-29.2)$ \\
\hline Wheezing & & & $51.5(24.7-107)$ & $49.7(23.8-104)$ \\
\hline Cough & & & $6.51(5.68-7.47)$ & $6.46(5.64-7.40)$ \\
\hline Acute bronchitis/bronchiolitis & & & $9.04(7.57-10.8)$ & $8.91(7.45-10.6)$ \\
\hline Acute upper respiratory tract infection & & & $1.47(1.26-1.72)$ & $1.47(1.26-1.72)$ \\
\hline Pneumonia & & & $2.10(1.44-3.07)$ & $2.11(1.44-3.09)$ \\
\hline Allergic rhinitis & & & $2.12(1.68-2.69)$ & $2.10(1.66-2.67)$ \\
\hline No. of contacts with GP & & & $1.10(1.08-1.12)$ & $1.10(1.08-1.12)$ \\
\hline Presence of parental asthma & & & & $1.74(1.41-2.15)$ \\
\hline Prescribing volume of GP & & & & $1.99(1.60-2.47)$ \\
\hline Patients $0-17$ y $\geq 25 \%$ per GP & & & & $0.59(0.44-0.78)$ \\
\hline \multirow{2}{*}{$\begin{array}{l}\text { Percentage of children with asthma } \\
\text { diagnosis per GP }\end{array}$} & & & & $0.88(0.83-0.93)$ \\
\hline & Variance (SE)c & Variance (SE) & Variance (SE) & Variance (SE) \\
\hline Between-family variance & $0.567(0.071)$ & $0.535(0.071)$ & $0.474(0.112)$ & $0.471(0.111)$ \\
\hline \multicolumn{5}{|l|}{ Between-GP variance } \\
\hline Age 1-17 y & $0.119(0.022)$ & & & \\
\hline Age $1-5 y$ & & $0.209(0.042)$ & $0.751(0.134)$ & $0.547(0.106)$ \\
\hline Age 6-17 y & & $0.097(0.022)$ & $0.384(0.071)$ & $0.214(0.047)$ \\
\hline \multirow[t]{2}{*}{ Covariance } & & $0.118(0.025)$ & $0.479(0.083)$ & $0.284(0.058)$ \\
\hline & Correlations & Correlations & Correlations & Correlations \\
\hline $\begin{array}{l}\text { Correlation of GP variance between } \\
\text { age-groups }^{d}\end{array}$ & - & 0.83 & 0.89 & 0.83 \\
\hline \multicolumn{5}{|l|}{ Intraclass correlatione } \\
\hline Age $1-17$ y & 0.17 & & & \\
\hline Age $1-5$ y & & 0.38 & 0.72 & 0.64 \\
\hline Age 6-17 y & & 0.29 & 0.65 & 0.51 \\
\hline \multicolumn{5}{|c|}{$\mathrm{Cl}=$ confidence interval; $\mathrm{GP}=$ general practitioner; $\mathrm{OR}=$ odds ratio; $\mathrm{SE}=$ standard error. } \\
\hline \multicolumn{5}{|c|}{$\begin{array}{l}\text { a Model } 1 \text { (age-groups), model } 2 \text { (age-groups, child characteristics), model } 3 \text { (age-groups, child characteristics, family characteristics, GP characteristics). } \\
\text { b In these models we corrected for the presence of an asthma diagnosis in the child (model 2: OR }=262 ; 95 \% \mathrm{Cl}, 219-312 ; \text { model 3: OR }=264 ; 95 \% \mathrm{Cl}, 221-315 \text { ). } \\
\text { ' The variance at the lowest level (children) is not determined because the outcome is dichotomous. }\end{array}$} \\
\hline
\end{tabular}




\section{Respiratory Morbidities Other Than Asthma}

As expected, we found that a diagnosis of asthma and typical asthmatic complaints, such as wheezing, were strongly associated with prescribing asthma medication. Our data, however, showed that asthma medication was used to treat not only asthma and asthmatic complaints but also other respiratory morbidities, such as acute bronchitis and acute upper respiratory tract infections. These findings are similar to findings from other studies showing a discrepancy between asthma medication use and asthma diagnosis, ${ }_{1}^{15,16}$ and they could indicate off-label use and overtreatment. Studies evaluating the effectiveness of asthma medication for indications other than asthma are inconclusive. ${ }^{27-30}$ The association between the child being male and receiving a prescription for asthma medication is in line with previous findings. ${ }^{14,31}$ Because none of the disease and complaints diagnoses showed a significant interaction with age, we can conclude that GPs do not regard certain complaints or illnesses as more or less important at a young age than at an older age when it comes to prescribing asthma medication.

\section{Limitations of the Study}

The current study has some limitations. First, the time relationship between the event of prescribing and the measurement of the independent variables was not evaluated. Also, we did not determine whether and for how long use of asthma medication was continued. Second, the complaints and disease diagnoses are not absolute characteristics of the child; they are registered by the GP and are the result of an interplay between the child with certain complaints and the interpretation of the GP. Further, possible differences in disease severity are not expressed in these dichotomized variables. Third, variables available to characterize GPs and families were limited. Model 3 shows how much of the variance is still unexplained after introducing the variables included in this model. Especially at the two higher levels, but also at the patient level, one could think of characteristics not available in our study that might be associated with prescribing asthma medication to children, including cultural and environmental factors (eg, particulate matter air pollution, indoor climate).

\section{Strengths of the Study}

The strengths of this study are the great number of children in our study population, the representativeness of the sample, and the data about diagnosing and prescribing derived directly from the GP's clinical records. Furthermore, the wide array of variables that might be associated with prescribing asthma medication, which we had available for a multilevel analysis, surpassed by far that of most available studies to date.
As a result, we were able to identify important factors associated with prescribing asthma medication to children and their independent contribution to the variance in prescribing. The relatively large variances found at the GP and family level indicate a substantial influence of both GP and family on prescribing asthma medication. As a consequence, a substantial sample size of GPs and families will be required to cross-validate these findings elsewhere.

In conclusion, our study showed that all 3 evaluated parties (patient, family, and GP) have a significant influence on whether children are given a prescription for asthma medication. At the level of the child we found that prescribing asthma medication was strongly related not only to asthma and asthmatic symptoms but also to many other respiratory diseases. Furthermore, health-seeking behavior, parental asthma, and the attitude and experience of the GP seemed to be associated with prescribing asthma medications to children. We found a much higher variance among GPs when prescribing to children younger than 6 years compared with older children, which we consider to be a result of the diagnostic complexities especially present in preschool children with asthmatic symptoms. Diagnostics uncertainties may result in more physician- and familydriven prescribing irrespective of the clinical context, a feature not always in the interest of the child.

To read or post commentaries in response to this article, see it online at http://www.annfammed.org/cgi/content/full/7/1/32.

Key words: Asthma/child; asthma/child, preschool; family practice; professional practice; multilevel; pharmacoepidemiology; prescribing

Submitted February 27, 2008; submitted, revised, June 11, 2008; accepted June 24, 2008.

Funding support: This study was partly funded by the National Institute for Public Health and the Environment (RIVM) and the Division of Pharmacoepidemiology \& Pharmacotherapy, Utrecht University, Utrecht, Amsterdam.

\section{References}

1. Masoli M, Fabian D, Holt S, Beasley R. The global burden of asthma: executive summary of the GINA Dissemination Committee report. Allergy. 2004;59(5):469-478.

2. O'Connell EJ. The burden of atopy and asthma in children. Allergy. 2004;59(Suppl 78):7-11.

3. Pocket Guide for Asthma Management and Prevention in Children, Revised 2006. Global Initiative for Asthma (GINA). http://www.ginasthma.org.

4. Townshend J, Hails S, McKean M. Diagnosis of asthma in children. BMJ. 2007;335(7612):198-202.

5. Townshend J, Hails S, McKean M. Management of asthma in children. BMJ. 2007;335(7613):253-257.

6. Bacharier LB, Boner A, Carlsen KH, et al. Diagnosis and treatment of asthma in childhood: a PRACTALL consensus report. Allergy. 2008;63(1):5-34. 
7. Cardol M, Groenewegen PP, de Bakker DH, Spreeuwenberg P, van Dijk L, van den Bosch W. Shared help seeking behaviour within families: a retrospective cohort study. BMJ. 2005;330(7496):882.

8. van Beijsterveldt CE, Boomsma DI. Genetics of parentally reported asthma, eczema and rhinitis in 5-yr-old twins. Eur Respir J. 2007;29(3):516-521.

9. Global Strategy for Asthma Management and Prevention. Global Initiative for Asthma (GINA). 2006. http://www.ginasthma.org.

10. British Thoracic Society. British Guideline on the Management of Asthma. A National Clinical Guideline. Revised ed. Scottish Intercollegiate Guidelines Network; 2007.

11. National Heart, Lung, and Blood Institute. Expert Panel Report 3: Guidelines for the Diagnosis and Management of Asthma, National Asthma Education and Prevention Program. 2007.

12. Clavenna A, Rossi E, Berti A, Pedrazzi G, De Rosa M, Bonati M. Inappropriate use of anti-asthmatic drugs in the Italian paediatric population. Eur J Clin Pharmacol. 2003;59(7):565-569.

13. Goodman DC, Lozano P, Stukel TA, Chang C, Hecht J. Has asthma medication use in children become more frequent, more appropriate, or both? Pediatrics. 1999;104(2 Pt 1):187-194.

14. Beimfohr C, Maziak W, von Mutius $E$, et al. The use of anti-asthmatic drugs in children: results of a community-based survey in Germany. Pharmacoepidemiol Drug Saf. 2001;10(4):315-321.

15. Stempel DA, Spahn JD, Stanford RH, Rosenzweig JR, McLaughlin TP. The economic impact of children dispensed asthma medications without an asthma diagnosis. J Pediatr. 2006;148(6):819-823.

16. Yeatts K, Davis KJ, Sotir M, Herget C, Shy C. Who gets diagnosed with asthma? Frequent wheeze among adolescents with and without a diagnosis of asthma. Pediatrics. 2003;111(5 Pt 1):1046-1054

17. Zuidgeest MG, van Dijk L, Smit HA, et al. Prescription of respiratory medication without an asthma diagnosis in children: a population based study. BMC Health Serv Res. 2008;8:16.

18. Westert GP, Schellevis FG, de Bakker DH, Groenewegen PP, Bensing $J M$, van der Zee J. Monitoring health inequalities through general practice: the Second Dutch National Survey of General Practice. Eur J Public Health. 2005;15(1):59-65.

19. Westert GP, Hoonhout LHF, De Bakker DH, Van den Hoogen HJM, Schellevis FG. Huisartsen met en zonder elektronisch medisch dossier: weinig verschil in medisch handelen. Huisarts Wet. 2002:45:58-62
20. Westert GP, Jabaaij L, Schellevis FG. Morbidity, Performance and Quality in Primary Care. Dutch General Practice on Stage. Oxford: Radcliffe Publishing; 2006.

21. Lamberts H, Wood M, Hofmans-Okkes I. The International Classification of Primary Care in the European Community. Oxford: Oxford University Press; 1993

22. Norwegian Institute of Public Health. WHO Collaborating Centre for Drug Statistics Methodology. Anatomical Therapeutic Chemical (ATC) Classification Index. http://www.whocc.no/atcddd/.

23. Beydon N, Davis SD, Lombardi E, et al. An official American Thoracic Society/European Respiratory Society statement: pulmonary function testing in preschool children. Am J Respir Crit Care Med. 2007;175(12):1304-1345

24. Bush A. Diagnosis of asthma in children under five. Prim Care Respir J. 2007;16(1):7-15.

25. de Jong BM, van der Ent CK, van Putte Katier N, et al. Determinants of health care utilization for respiratory symptoms in the first year of life. Med Care. 2007;45(8):746-752.

26. Bokhour BG, Cohn ES, Cortes DE, et al. Patterns of concordance and non-concordance with clinician recommendations and parents' explanatory models in children with asthma. Patient Educ Couns. 2008;70(3):376-385. Epub 2007 Dec 26.

27. Smucny J, Becker L, Glazier R. Beta2-agonists for acute bronchitis. Cochrane Database Syst Rev. 2006;(4):CD001726.

28. Blom D, Ermers M, Bont L, van Aalderen WM, van Woensel JB. Inhaled corticosteroids during acute bronchiolitis in the prevention of post-bronchiolitic wheezing. Cochrane Database Syst Rev. 2007;(1): CD004881.

29. Bisgaard H, Hermansen MN, Loland L, Halkjaer LB, Buchvald F. Intermittent inhaled corticosteroids in infants with episodic wheezing. N Engl J Med. 2006;354(19):1998-2005.

30. Chavasse R, Seddon P, Bara A, McKean M. Short acting beta agonists for recurrent wheeze in children under 2 years of age. Cochrane Database Syst Rev. 2002;(3):CD002873.

31. Wright AL, Stern DA, Kauffmann F, Martinez FD. Factors influencing gender differences in the diagnosis and treatment of asthma in childhood: the Tucson Children's Respiratory Study. Pediatr Pulmonol. 2006;41(4):318-325. 